Canadian Studies in Population, Vol. 33.2, 2006, pp. 139-154

\title{
Demographic Decisions and Demographic Well-Being
}

\author{
Fernando Rajulton \\ Population Studies Centre \\ Department of Sociology \\ University of Western Ontario \\ London, Ontario, Canada
}

\author{
Presidential Address, Canadian Population Society \\ University of Western Ontario, London, Ontario
}

June 3, 2006

It may come as a surprise to many of you to see a title like this coming from me as my Presidential Address. To tell you the truth, I have been toying with many ideas until last week when I finally decided to deliver my address on this topic. My decision is certainly not a demographic decision, but it is a decision driven mostly by its aptness to honor the contributions made not only by our honoree, Doug Norris, but also by many of us during our lifetime. Although at first sight the topic doesn't seem to be related to mathematical demography, all the ideas I am sharing with you today are coming from the rich research experience of demographers, in particular mathematical demographers.

I decided to speak on this topic because of the recent events in demographic research circles in Canada. You may be aware of the contributions the demographers are making toward Canadian social policies through the workshops and conferences organized by Human Resources and Social Development Canada (HRSDC) and Policy Research Initiative (PRI) during the past few months. We are happy to see this turn of events, especially among the government agencies to listen to what demographers have to say. At the same time I am a bit concerned too because of what we have learned from the history of our neighboring country south of the border. Let me say a few words about that history to inform those who are not aware of it and to remind those who already know it. 
It was in the year 1969 when the then US President Richard Nixon convened the Rockefeller Commission on Population Growth and the American Future to evaluate the challenges posed by continued population growth in the US. In his speech to the Congress, Nixon said "...perhaps the most dangerous element in the present situation is the fact that so few people are examining these questions from the viewpoint of the whole society... In the governmental sphere, there is virtually no machinery through which we can develop a detailed understanding of demographic changes and bring that understanding to bear on public policy" (Nixon, 1969; italics mine). Such a wonderful testimony to the important role of demography in public policy simply could not have come from a politician. I am sure a demographer should have written it. I would strongly encourage you to read it, if you have not already done so. What happened after that remarkable speech by Nixon is history. Three years after Nixon's speech, the Rockefeller commission came with its many recommendations, at least two of which (universal access to contraception and liberalizing abortion laws) were politically abhorrent to Nixon who dismissed entirely the work of the Commission. Charles Westoff, the executive director of the Commission wrote in the journal Population Index (1973:501) that "The President's response issued in May 1972 was a disappointment at every level....In effect, the responses were narrowly political and greatly at variance with the concerns about population that the President had expressed less than three years earlier". History is known to repeat itself. But I hope we will not face a similar situation, given the changing political landscape of Canada today.

We should be glad about the turn of events at the federal agencies and we hope that same interest will permeate the policy making agencies in the provinces. Policy makers are becoming more aware of the importance of studying the demographic changes and their implications for social policies. In a way, policy makers are beginning to realize that "Demography, the study of human populations, is the most powerful - and most underutilized - tool we have to understand the past and to foretell the future. Demographics affect every one of us as individuals, far more than most of us have ever imagined. They also play a pivotal role in the economic and social life of our country." (Foot, 1998:2).

Following Hauser and Duncan (1959:2), we are used to defining demography in our lectures as "the study of the size, territorial distribution, and composition of population, changes therein, and the components of such changes". It is fitting that this definition includes two important phrases - "composition of population" and "changes therein". These two phrases broaden demography to encompass many disciplines and we are often proud to say that Demography is essentially interdisciplinary. Despite the sometimes acrimonious academic squabbles between demographers and sociologists seen in some university departments, it is hard to imagine whether social science - any social science, for that matter - 
Fernando Rajulton

can advance at all as a science without first knowing the basic information about the human population that it studies.

\section{Demographic Decisions}

Composition of a population and changes therein essentially imply that individuals in a population or a society are making decisions in their daily lives that affect the composition of the population in many ways. As we know only too well, it is the day-to-day demographic decisions of individuals in a society let me stress the term "demographic" here because not many think of it that way - that shape and determine not only the three basic components of population growth, namely fertility, mortality and migration but also all other related behaviors.

People make a variety of demographic decisions for many reasons. Mortality seems to be an exception, at least until now. Except for a few who approach Doctor Death or commit suicide, people do not decide to die, not only because nobody willingly likes to die but also because whether we like it or not, we all die anyway. Otherwise in all other spheres of life, which can be classified into three main forms, namely the Self, the Intimate and the Social (McDonald, 1996), people make decisions all the time. People decide to migrate looking for greener pastures to improve their lives. People decide to marry, cohabit or form a couple relationship, whether of the same or opposite sex. People decide to have children or not, which in our times is more than ever closely associated with the idea of liberation, especially of women. [Just a few days ago I heard the expression "childless" has fallen out of use in Europe; people prefer to use the expression "childfree" instead - well, what a great liberation!] People decide to divorce and remarry. The Federal Act of Divorce 1968 had spelled out several conditions for hearing the case for divorce such as adultery, mental or physical cruelty, homosexual conduct, addiction to alcohol or narcotics and separation for three years or desertion for five years. A divorce was granted in two steps and the second step, the decree, was necessary for remarriage. The Divorce Act of 1985 simplified everything. Divorce is granted on only one condition: breakdown of marriage, established by proof of adultery, mental or physical cruelty, or separation for one year. The impact of this change in the Divorce Act is quite clear. When I was coming by bus yesterday to York University from the Downsview metro station, I saw several ads at a bus stop. There were ads like "Quick driving test", "Quick BA Diploma", and so on. And I noticed surprisingly an ad that read "Quick Divorce - from $\$ 300$ ". The point here is that social policies have tremendous impact on people's demographic decisions. We shall come back to this point later. 
Over the past three decades, changes in social attitudes, family laws and social security provisions have led to significant changes in the way people make their demographic decisions. These demographic decisions can create all the differences in a nation and between nations. Small changes introduced by demographic decisions that people make daily can accumulate over time, introduce further changes in social attitudes and behavior, thus eventually creating a "distinct" society or nation. Changes in patterns of marriage and fertility or, in general, family transformations that we witness today, are actually the accumulated outcomes of millions of personal demographic decisions made by men and women of past generations. In a recent paper that examines the socalled "fertility divide" among Canadian and American women, Torrey and Eberstadt (2005) point out that differences in fertility in Canada and the US may say less about the future than about the present. These two societies are becoming different at the same time as their economies integrate and become more interdependent. Why then the fertility divide? The answer lies in the fact that the "basic rhythms of private lives are diverging as women in Canada enter common-law unions more often, wait longer than American women to marry, and have children later and less often". We know fertility is a leading indicator of other changes taking place in a society. If the North American fertility divergence continues, Canada and the US may become an example of how countries can converge at the macroeconomic level while diverging at the micro level of individuals and families. Micro- and macro-economic explanations of demographic behavior, in particular fertility behavior, might have helped us to explain historical transitions in the past but their explanatory power becomes minimal beyond a certain threshold of development and individualism.

\section{Demographic Well-Being}

Like all decisions, demographic decisions have a future orientation and impact. We have expectations or hopes about how a specific demographic decision that we make will affect our lives. In general, we do not think about how these decisions will affect our society at large. Some of these demographic decisions are definitely at the top of the list in terms of our own well-being and purpose in life. Forming and dissolving couple relationships, having children and moving to greener pastures are certainly important life events that enrich our own wellbeing and purpose in life. We are more than willing to "grin and bear" any hardships or difficulties that may accompany these decisions and to go through any amount of social adjustment associated with those decisions. What we do not normally think about is the fact that these demographic decisions not only enrich our own well-being and purpose in life but they enrich also the wellbeing of the society we live in. It is this well-being of the society at large that I am calling here "demographic well-being". 
You may be wondering why I am interested in thinking about demographic well-being. It all started with the discussion the group of demographers at Western had a few months ago over the life course framework we were proposing to PRI. Connecting the different life events, we were brainstorming about what these events finally lead to. Then, all of us agreed that all life events eventually lead to our well-being. It is certainly a good idea. Since then I have been musing about what sort of well-being are we really thinking of? This presidential address is the outcome of my musing over the last few weeks. Not all ideas can be expressed in a short time allocated to this address, but I shall be content with pointing out a few directions for others to pursue.

First, that there is something like demographic well-being is not usually said or heard in our discourses or research works except for implicit implications of what would happen if that demographic well-being is not there, for example, an ageing society. Do we need a new expression "demographic well-being" at all? Why can't we be simply happy with the term already in use such as, for example, social well-being? Or, do not the two terms - social and demographic well-being - mean the same thing? You may think otherwise. But I am here arguing for using the term "demographic well-being" (DWB), because the wellbeing that follows demographic decisions has a unique characteristic that is not found in other types of well-being, say social well-being. Decisions made by us as individuals are personal and demographic, they are not personal and social. Times are gone when demographic decisions were considered to be social. For example, in the past a marriage was considered to be, not so much a personal decision; it was fundamentally a family or social decision. So too was childbearing. In our times, demographic decisions have become more and more personal, based on personal autonomy, growth and fulfillment. In fact, societies (especially developed societies) have made various accommodations in their legal and constitutional rights of individuals such that these decisions have become more and more personal and "individualistic", no longer "social". As I am going to say later, societies have experimented with this as a sort of "solution" to the problems raised by changing demographic decisions of people.

Second, I prefer to use the term "demographic well-being" because it exists in its own right. It is not the same thing as "social well-being". Rather, if we think carefully, demographic well-being (DWB) leads to social well-being (SWB). $S W B$ follows DWB, not the other way.

Third, I am arguing for using the expression DWB not only because of my professional bias towards demography (which should be obvious!) but also because of my personal, professional bias toward putting other expressions of well-being in their proper place, especially those that have been overemphasized 
in our daily thinking, reading and living. This point may become clear with what I have to say in the following paragraphs.

I was curious to find out the number of instances the expression "demographic well-being" is used at all in any literature. I searched through the web pages and went through so many papers, scientific and nonscientific. I found only a handful of instances where the expression "demographic well-being" is explicitly used. To my surprise and delight, one of these instances is the web page maintained by the province of Newfoundland and Labrador which mentions clearly the province's programs are geared toward the "social and demographic well-being" of people (see, for example, the province's web page at http://www.releases.gov.nl.ca/releases/2002/exec/0916n05.htm).

Researchers use the term "well-being" under many aspects. The most often used expression is economic well-being; in fact, "well-being" is simply equated to "economic well-being", nothing else matters. We can also hear frequently in discussions and research papers the term well-being used exclusively to imply health, in particular physical health. Beyond the health aspect, we hear of "psychological well-being", "consumer well-being", "emotional well-being", "subjective well-being", "sexual well-being", and, somewhat rarely compared to others, "social well-being" (implying mostly participation, belonging and tolerance). These different aspects of well-being are certainly not mutually exclusive; they often overlap; so too research on well-being. We can add to this list any number of other aspects of well-being. But personally, perhaps because of my professional bias again, I prefer to look at them all as offshoots of DWB because none of them can exist without $D W B$.

In the current literature on well-being, economic well-being is the most frequently talked about, no wonder because of the obsession with economic growth and the money it would bring into our pockets. Politicians do not hesitate to talk about the "money in your pockets", and two to four hundred dollars more in people's pockets seem to sway their votes from one political party to another. Our economy has recently shown good signs of growth which may continue sometime into the foreseeable future. But has it really improved the economic well-being of Canadians? Many studies indeed show a decline in well-being, not only economic but also social and other aspects of well-being.

Consider, for example, the persistent economic or income disparity among families that many research papers talk about. Since 1970s, the rich are getting richer and the poor are getting poorer. Real average family income has definitely increased over time (30 to $40 \%$ ), however this increase is not spread evenly across all families. (Statistics Canada, 1999). What is important to stress here is the difference in income disparity has to do with the demographic changes in 
Fernando Rajulton

family structure and the changing nature of families. Thus, in the 70s, those aged 65 dominated the bottom decile of income; extreme poverty was a problem of the old. In 1995 and thereafter, the elderly had been replaced by female single parents, who accounted for $24 \%$ of the bottom decile in the seventies but a whopping 40 percent in 1995.

In general, the so-called "economic explanations" of demographic decisions with which we are only too familiar, have not ultimately explained much of demographic decisions after all. Consider all the economic explanations researchers have explored to explain fertility, for example. As pointed out earlier, two nations can converge economically but at the same time diverge in their value systems and hence in their fertility. I am personally glad to see that more recent demographic research works try to de-emphasize the economic rational choice theory and to focus more on social and psychological theories of demographic behavior (see, for example, the program on Institutional and Political Approaches to Family and Fertility Dynamics at Max Planck Institute for Demographic Research, Rostock, available at http://www.demogr.mpg.de/general/structure/division2/lab-ceffd/49.htm]. I am not saying that economic factors do not at all play their role in demographic decisions, far from it. But, to give such an important place to economic rationality is unwise and fruitless.

\section{Implications of Demographic Decisions and Demographic Well-Being}

What then are the implications if we talk about demographic well-being ensuing from demographic decisions? The first obvious implication is the way we try to explain demographic decisions. As said earlier, individual choice and decisions cannot be simply considered as the rational man maximizing his "utility", whatever that ambiguous term may mean. Rather, they need to be considered within the "cultural" or "sociodemographic" context in which the decisions are made. This context may include hard to measure factors such as power, status, politics, networks, values, social policies, and so on.

The second implication is the greater role the age structure should play in our research. The unique way of capturing the changes introduced by demographic decisions is to study the age structure changes, classified by various dimensions of well-being one can see as relevant. As we are all aware, declining fertility, not so much declining mortality, has far-reaching ripple effects on the age structure. They touch on all age-specific activities and programs throughout society. Here is the age structure of Canadian population from Census 2001 (see Figure 1). Instead of just looking at the age structure for the whole population, let us look at it, for example, by immigrant status (for simplicity, born in Canada 


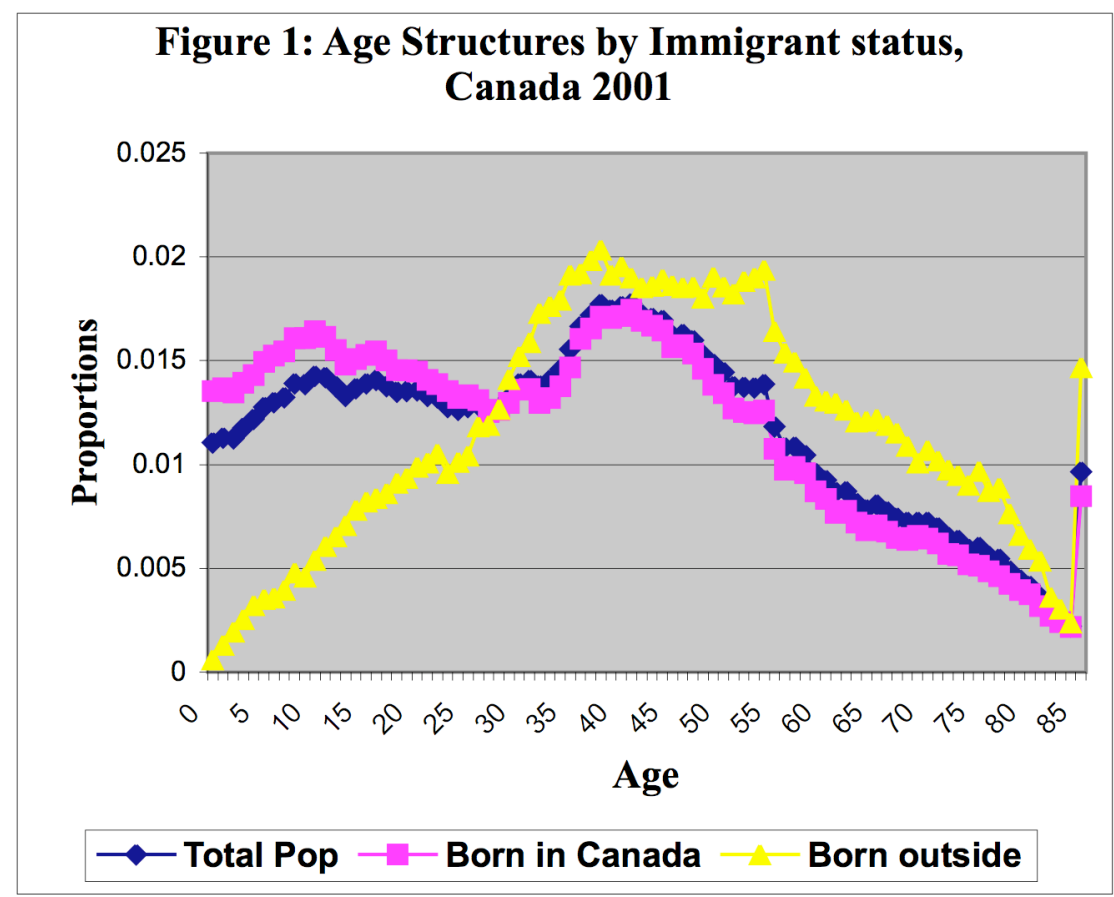


Fernando Rajulton

and born outside Canada). It is striking that the proportions in the younger age groups among the Canadian-born are higher than those among the foreign-born. Note that these Canadian-born include children born to the foreign-born as well. In contrast, the proportions of foreign-born children and young adults are remarkably lower than the overall age structure. Above age 18, the Canadianborn age structure and the total population's age structure almost perfectly coincide. We can also note the remarkable contributions made by the adult foreign-born to the age structure of the Canadian population.

As a second example, if one is interested in the economic aspect of age structure, one can look at the age structure by employment status (see Figure 2). The picture is quite interesting and calls for more serious examination in terms of demographic well-being of Canadians, not only in the present but also in the future.

Talking about the age structure, an important question for further research would be: Is there then anything like an "optimal age structure"? This question resembles the question that has been debated for centuries in human history, namely the optimum population size. But it is not simply an optimum size that we are talking about here, rather the question is about an optimum age structure. It would be worth investigating further the optimum age structure with respect to certain key aspects of well-being. An interesting case would be, for example, what would be the optimal age structure that would enable us to preserve the social benefits well into old age. As far as I know, there was only one study published more than two decades ago, by Martin Feldstein of Harvard University, that examined a point somewhat related to this.

I would like to emphasize here that the concept of optimal age structure is different from what some researchers are talking about these days as "demographic gift"- an expression referring to the age structure found in many developing countries, consisting of relatively fewer dependent children and relatively few elderly, but with a larger share of working age population (Bloom and Williamson,1998; Birdsall et al., 2001). During the IUSSP conference in Tours I heard this expression so often used by researchers from developing countries, particularly from Africa. They all express an optimistic view that such an age structure is a "blessing" to their developing countries unlike the problems faced by developed societies. No, such an inference is a bit naïve, if such a "demographic gift" is not going to be accompanied by other aspects of wellbeing as well, besides the fact that with declining fertility such a "gift" can only be considered as a temporary phenomenon. 


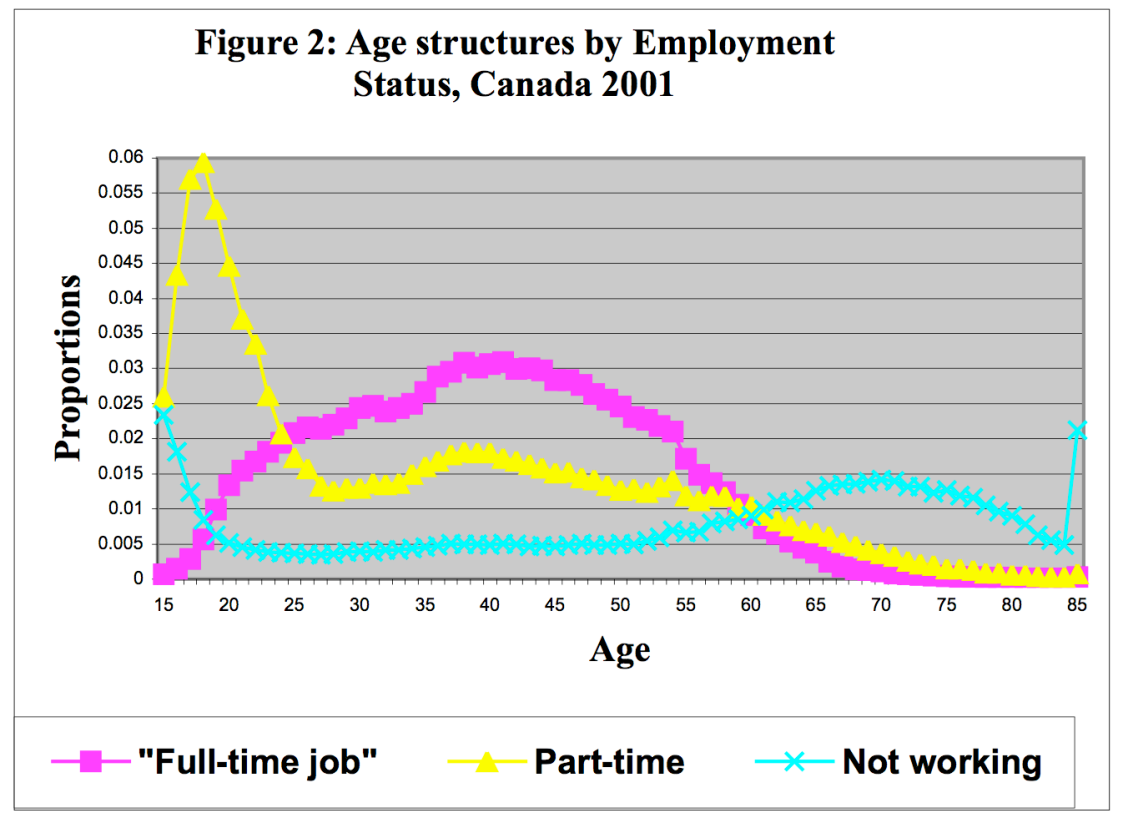


The third implication is that people themselves are ultimately responsible to bear the future implications of their own demographic decisions in terms of demographic well-being. An interesting and current phenomenon that we are witnessing today is what the baby boomers are experiencing and are going to experience in the future. As Easterlin, Schaefer, and Macunovich (1993) argued more than a decade ago, the baby boomers delayed marriage (or never married) and had fewer children in order to narrow the gap between their real and expected levels of income (compared to their parents' income). The important demographic decision the baby boomers made, namely increasing participation of women in the labor force and forgoing childbirth, obviously helped them to become markedly better-off economically than their predecessors. But as Easterlin and colleagues argued, they may have sacrificed their demographic well-being in order to achieve their economic prosperity or economic wellbeing. "In effect, an improvement in the economic status over that of their parents was purchased at the expense of family life" (p. 513). The baby boomers were and are economically better-off but they are poorer in terms of demographic well-being. Therefore, a large number of baby boomers will be forced to face retirement without the financial and emotional support of adult children or a spouse. They are responsible for the DWB they have created through their own demographic decisions. No society and no government can be expected to perform miracles in the absence of DWB without adversely affecting the DWB of future generations.

The fourth implication is the role of policies for DWB. Most policy makers in developed societies like Canada consider "tampering" with people's demographic decision-making anathema to the democratic process. Our political systems and policy making bodies are under the impression that demographic decisions are made exclusively by individuals without any influence from government policies. This becomes quite evident when we discuss with policy makers. But there is an irony here. While childbearing is considered a deeply personal matter that is resolved only in the "bedrooms of a nation" or that should be left entirely to the individuals and not to governments, the other demographic processes, especially mortality/health and migration, are very much the concern of governments. By refusing to engage in all demographic decision making processes, many are blind to the future consequences of these processes, hence of demographic well-being, affected by all policies that have indirect impact on people's demographic decisions every day. All policies, whether explicitly demographic or not, are implicitly demographic, and they all have enormous demographic consequences for the future. It is worrisome then that most policies occur in our country without proper demographic scrutiny. Sometimes we wish that while framing policies, politicians would think more about future consequences of the demographic decisions of today than their own partisan convictions and conventions. 
Peter Hicks, before becoming the Assistant Deputy Minister of Social Development Canada, wrote a report on Preparing for Tomorrow's Social Policy Agenda (Hicks, 2002). In that report, he suggested in Section 5 titles "Planning for an uncertain future: Three scenarios" that policy research and development be consistent with a wide range of plausible future policy directions. The development work he proposed in that report touched on three different scenarios about the future. The third scenario he proposed was what he called "Life Is Citizenship". This scenario puts more emphasis on the interrelations among the various domains of life, "including caregiving and the non-market domains of society as well as greater collective effort in building social infrastructure, particularly around housing and caregiving of children and seniors, including a concern about fertility levels" (p.15)

These various domains of life as citizens are what are ultimately meant by the expression DWB. Whenever I teach courses in demography, at the beginning of the course, I define demography, as we all do, using the above quoted Duncan and Hauser's words. And then, I tell students what the word "demography" ultimately means. Summarizing all the debates over the centuries about human population, I learned the Chinese had a wonderful way of expressing what "demography" or simply "population" means. Here is the Chinese word for population - rán kău - a pictograph (see Figure 3), that tells us what exactly demography is all about. Demography $=$ Person + a mouth to feed + a house to shelter. Policies need to address these two domains first, namely food and housing. Peter Hicks mentioned them in the Report. I am afraid, they unfortunately stay on the report.

Food banks and shelters for the homeless are reporting conspicuous increase in the number of people who need their support. It would be worthwhile to examine seriously the trends in these two basic aspects of DWB. Even if people have their homes, the question of affordability is a more serious concern than ever. In a study that I did recently on housing and housing conditions in Canada using the 2001 Census, it was clear that only three fourths of Canadian households meet the affordability criterion (defined as spending less than $30 \%$ of before-tax household income on shelter costs). Eighty-four percent of owners spend less than $30 \%$ of their incomes on housing, while only sixty percent of renters do so (see Table 1). Further, variations by household type or by family structure are once again apparent here. Challenges in providing affordable housing to all citizens of the country are many. But one is struck with the silence on the part of governments, either federal or provincial, on this primary DWB, especially in many of Canada's major urban centres. 
I do not mean to criticize the policy making processes in our nation. In fact, if we study the past, we cannot but admire how our society and social policies over time have made various adjustments to find a societal solution to the conflict people experience in their day-to-day life because of their demographic decisions. Our social policies have indeed tried to find a societal solution to this increased conflict, to ameliorate the impact of this conflict. Greater flexibility in the ways we can arrange or break our relationships, newer and greater support in combining work and family responsibilities, tolerance of alternative lifestyles are all major social changes brought about by various social policies in Canada. At the same time, however, it is good to study in depth what kind of demographic well-being do these changes entail for the future. As said earlier, these changes have far lasting consequences.

To summarize the ideas that I have shared with you here, let me put it this way. We are at a point in history when demographic decisions and demographic wellbeing are in our own hands, not in the hands of policy makers, and not in the hands of governments. And, it is important for all of us to bear in mind that our demographic decisions of today will make the destiny of our nation tomorrow.

\title{
Figure 3: Chinese word for Population
}

\author{
人口 \\ 人一 person \\ $\square-$ mouth; also is used to be a unit \\ when counting a group of people
}


Demographic Decisions and Demographic Well-Being

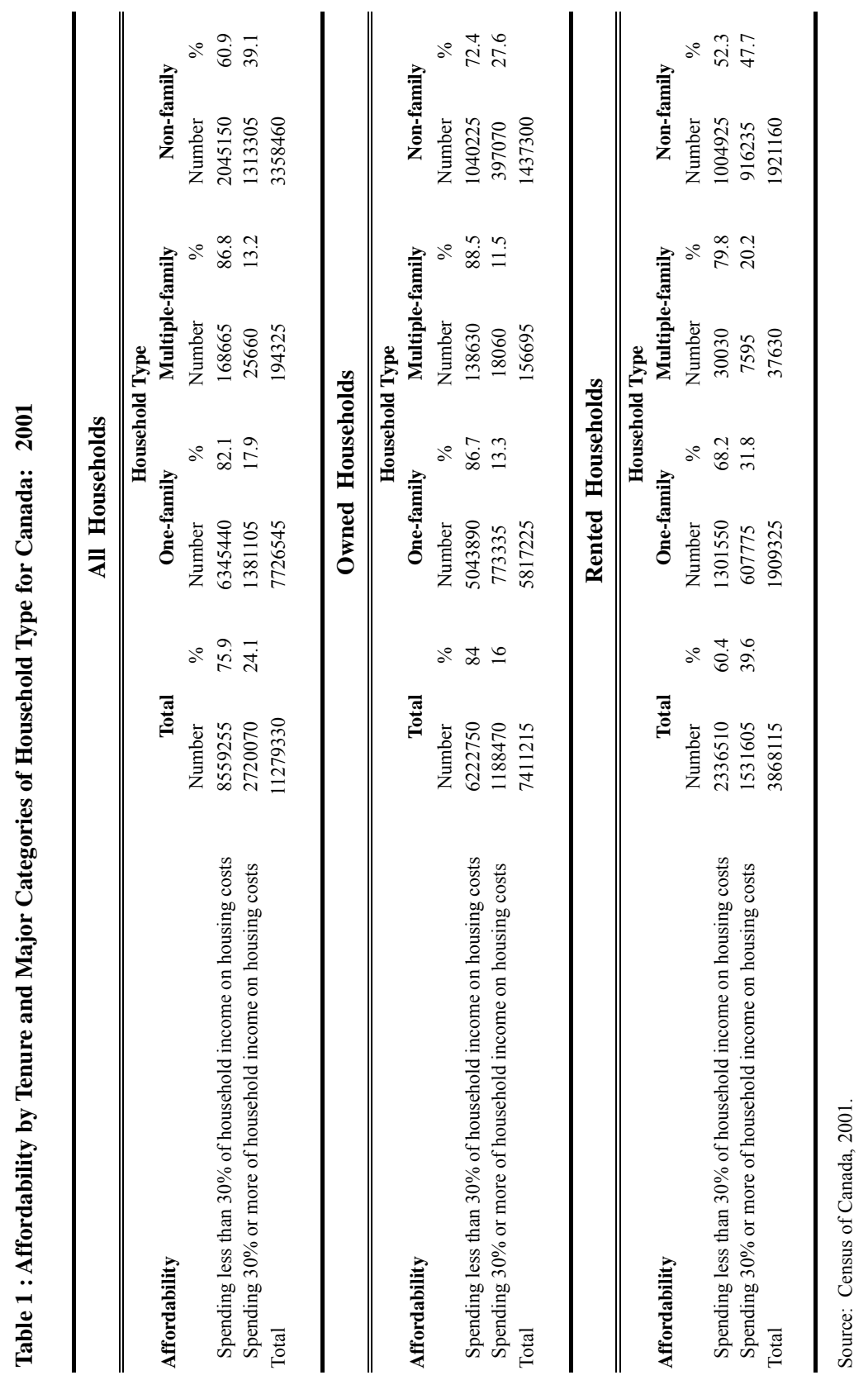


Fernando Rajulton

\section{References:}

Birdsall, Nancy, Allen C. Kelley and Steven W. Sinding, eds., 2001. Population Matters: Demographic Change, Economic Growth and Poverty in the Developing World. Oxford: Oxford University Press.

Bloom, David E. and J. G. Williamson, 1998. "Demographic Transitions and Economic Miracles in Emerging Asia." World Bank Economic Review 12(3): 419-56.

Easterlin, R.A., C.M. Schaeffer, and D.J. Macunovich, 1993. Will the baby boomers be less well off than their parents? Income, wealth, and family circumstances over the life cycle in the United States. Population and development Review, Vol.19, No.3, pp. 497-522.

Feldstein, Martin S, 1990. Imperfect annuity markets, unintended bequests, and the optimal age structure of social security benefits. Journal of Public Economics, 1990, vol. 41, issue 1, pages 31-43

Foot, David K., 1998. Boom, Bust and Echo 2000. Toronto: Macfarlane Walter and Ross.

Hauser, Philip M. and Otis D. Duncan, eds. 1959. The Study of Population: An Inventory and Appraisal. Chicago: The University of Chicago Press.

Hicks, Peter, 2002. Preparing for tomorrow's social policy agenda: New priorities for policy research and development that emerge from an examination of the economic well-being of the working-age population. Social Research and Demonstration Corporation (SRDC) Working Paper Series 02-04. Human Resources and Development Canada (HRDC): Ottawa.

McDonald, Peter, 1996. Demographic life transitions: an alternative theoretical paradigm. Health Transition Reveie, Supplement 6, pp. 385-392.

Nixon, Richard M., 1969. Special Message to the Congress on Problems of Population Growth, July 18, 1969. Public Papers of the Presidents, No. 271, Washington, DC: Office of the Federal Register, National Archives, 1970, p. 526. 
Demographic Decisions and Demographic Well-Being

Statistics Canada, Family Income 1970-1995 [internet], 1999, March 9.

Available from

http://www.statcan.ca/Daily/English/990303/d990303.htm\#FEATURES.

Torrey, Barbara B. and Nicholas Eberstadt, 2005. The northern America fertility divide. Policy Review, Vol. 132, August \& September 2005. Hoover Institution: Washington DC.

Westoff, Charles, 1973. The Commission on Population Growth and the American Future: Its Origins, Operations and Aftermath. Population Index, Vol. 39, No. 4. Princeton, NJ: Office of Population Research, Princeton University. 